\title{
Avaliação físico-química de filés de tilápia (Oreochromis niloticus) submetidos à sanitização
}

\author{
Physical-chemical evaluation of "tilápia" (Oreochromis niloticus) fillets submitted to sanitization
}

\author{
Nelma de Mello Silva OLIVEIRA ${ }^{1 \star}$, Wilson Roberto Mesquita OLIVEIRA ${ }^{1}$, Luiz Carlos NASCIMENTO ${ }^{1}$, \\ José Mauricio Schneedorf Ferreira da SILVA², Eduardo VICENTE³, João Evangelista FIORINI ${ }^{1}$, \\ Maria Cristina BRESSAN ${ }^{4}$
}

\begin{abstract}
Resumo
No presente trabalho foi avaliado o efeito dos agentes sanificantes dicloroisocianurato de sódio na concentração de 3 a 3,5 mg. $\mathrm{L}^{-1}$ (T1), dicloroisocianurato de sódio associado ao ultra-som (T2), ozônio na concentração de 3 a $3,5 \mathrm{mg} \cdot \mathrm{L}^{-1}$ (T3), ozônio associado ao ultra-som (T4) e controle (T5) sobre a composição centesimal, perfil de ácidos graxos (AG), teor de colesterol e índice de peróxido de filés de tilápia. Os tratamentos afetaram $(\mathrm{p}<0,05)$ a composição centesimal. Os filés foram tratados por imersão, durante 20 minutos, em soluções que apresentavam pH 6,0 e temperatura de $5{ }^{\circ} \mathrm{C}$. Os sanificantes causaram uma perda de água e aumentaram a concentração de proteínas no filé, tendo esse fato sido notado mais acentuadamente no T3 (77,16\% de umidade e 19,73\% de proteína) quando comparado ao T5 (78,60\% de umidade e $18,71 \%$ de proteína). Foi demonstrada diferença significativa (p < 0,05) na fração lipídica para ácidos graxos saturados (AGS), ácidos graxos monoinsaturados (AGM) e ácidos graxos polinsaturados (AGP) entre os tratamentos propostos. Os AGS apresentaram diferença entre os T3, T4 e T5, com as respectivas médias 37, 33,50 e 36,30\%. Os T1 e T2 (34,90 e 34,80\%) não diferiram entre si, mas foram diferentes dos T3, T4 e T5 (39,30, 36,30 e 39,10\%) para AGM. O T3 foi o que mais preservou a fração AGM. Os AGP não apresentaram diferença entre os T1 e T2 (23 e 22,50\%) e os grupos T3, T4 e T5 (18,30, 20,40 e 17,70\%) diferiram entre si, tendo o T1 apresentado as maiores médias. Obtevese uma redução mais acentuada do nível de colesterol no grupo T2 (43,94 mg.100 g $\left.{ }^{-1}\right)$ quando comparado com T5 (54,77 mg.100 g-1). Os teores médios de peróxido encontrados nos filés submetidos aos tratamentos não revelaram diferença estatística segundo análise de variância ( $\mathrm{p}>0,05)$, apesar dos valores serem bastante diferentes, apresentando uma variação de 6,07 a $39,57 \mathrm{meq} \cdot \mathrm{kg}^{-1}$.

Palavras-chave: análise centesimal; ácidos graxos; colesterol; peróxido; tilápia (Oreochromis niloticus).
\end{abstract}

\begin{abstract}
The present research had as objectives to study the effects of chlorinated water (sodium dichloroisocyanurate -3 to $3.5 \mathrm{mg} . \mathrm{L}^{-1}$ ) (T1); chlorinated water associated to ultrasound (T2); ozonated water ( 3 to $\left.3.5 \mathrm{mg} . \mathrm{L}^{-1}\right)$ (T3); ozonated water associated to ultrasound (T4), and control (T5) on the centesimal composition, fatty acid profile, cholesterol content and peroxide value in "tilápia" fillets. The fillets were treated by immersion in the solutions, at $\mathrm{pH} 6.0,5^{\circ} \mathrm{C}$, for 20 minutes. The treatments affected the centesimal composition. Sanitizers caused a loss of water and increased the concentration of protein in the fillets, more strongly in T3 (77.16\% moisture and 19.73\% protein), when compared to T5 (78.60\% moisture and $18.71 \%$ protein). Significant differences were observed for saturated fatty acids (SFA), monounsaturated fatty acids (MUFA) and polyunsaturated fatty acids (PUFA). SFA presented differences in T3, T4 and T5, with the respective averages of 37, 33.50 and $36.30 \%$. T1 and T2 (34.90 and 34.80\%) did not present differences, but were different from T3, T4 and T5 (39.30, 36.30 and 39.10\%) for MUFA. T3 preserved more fractions of MUFA. PUFA did not differ in T1 and T2 (23 and 22.50\%) and T3, T4 and T5 (18.30, 20.40 and 17.70\%) differed from eachother, with T1 presenting the highest averages. There was a marked reduction in the level of cholesterol in T2 $\left(43.94 \mathrm{mg} .100 \mathrm{~g}^{-1}\right)$, when compared to T5 $\left(54.77 \mathrm{mg} .100 \mathrm{~g}^{-1}\right)$. There was no statistical difference in peroxide level among the treatments.

Keywords: centesimal composition; fatty acids; cholesterol; peroxide; fillets; Oreochromis niloticus.
\end{abstract}

\section{Introdução}

Pescados apresentam condições intrínsecas que propiciam a multiplicação microbiana, podendo reduzir a vida útil do produto, que passará a representar risco à saúde pública. A elevada atividade de água, a composição química, o teor de gorduras insaturadas facilmente oxidáveis e o $\mathrm{pH}$ próximo da neutralidade da carne de peixe são os fatores determinantes no crescimento microbiano.
Os lipídios de pescado contêm quantidades elevadas de ácidos graxos insaturados, que são suscetíveis à oxidação (ANKADE, 1989). Essas reações de oxidação ocorrem por formação de radicais livres e se caracterizam por um período de indução, seguido por uma absorção acelerada de oxigênio, e terminam com a produção de peróxidos, odor, ranço e outros produtos de polimerização (BOBBIO; BOBBIO, 1992). A velo-

Recebido para publicação em 1/9/2006

Aceito para publicação em 20/12/2007 (001838)

${ }^{1}$ Laborátorio de Biologia e Fisiologia e Microrganismo, Universidade José do Rosário Vellano, Rua Antônio Esteves, 424, Jd. Aeroporto, CEP 37130-000, Alfenas - MG, Brasil,

E-mail:nelma.oliveira@unifenas.br; nelmao@terra.com.br

2 Universidade José do Rosário Vellano - UNIFENAS

${ }^{3}$ Instituto de Tecnologia de Alimentos - ITAL, Centro de Química e Nutrição Aplicada

${ }^{4}$ Departamento de Ciência dos Alimentos - DCA, Universidade Federal de Lavras - UFLA

${ }^{*}$ A quem a correspondência deve ser enviada 
cidade de reação do oxigênio e dos lipídios pode ser retardada pela adição de antioxidantes que atuam rompendo a cadeia de radicais livres ou decompondo os peróxidos. Os perigos alimentares de ingestão de lipídios de pescado oxidados são decorrentes dos peróxidos e das reações que estes possam desencadear no organismo humano. Em geral, os efeitos de óleo de pescado oxidado refletem danos secundários com a formação de radicais livres a partir da decomposição dos peróxidos (BEIRÃO et al., 2003; FULLER; JIALAL, 1994).

A utilização de agentes sanificantes contribui para o aumento da vida de prateleira do produto resfriado. Os métodos utilizados são químicos e físicos, tais como: o cloro, o ozônio e o ultra-som, que podem ser utilizados, associados ou não a outros métodos (RICE, 1996; TORRES et al., 1996). O presente estudo objetivou analisar o efeito destes sanificantes sobre a composição centesimal, perfil de ácidos graxos(AG), teor de colesterol e índice de peróxido, para observar uma possível degradação dos constituintes presentes na carne de tilápia.

\section{Material e métodos}

Um total de 20 filés de tilápia, divididos aleatoriamente em 5 grupos e submetidos aos tratamentos: (T1) água hiperclorada (3 a 3,5 mg.L-1 ); (T2) água hiperclorada + ultra-som; (T3) água ozonizada (3 a 3,5 mg. $\mathrm{L}^{-1}$ ); (T4) água ozonizada + ultra-som e (T5) controle. Os tratamentos foram por imersão dos filés em solução, à temperatura de $5{ }^{\circ} \mathrm{C}$, em cuba lavadora ultra-sônica por 20 minutos (as concentrações foram monitoradas a intervalos de 5 minutos).

A composição centesimal realizada se deu a partir da extração de proteína bruta, que foi quantificada pelo método de análise de Kjeldahl; e de lipídios totais, que foram determinados pelo método de Soxhlet. A umidade em estufa a $105^{\circ} \mathrm{C}$ até a obtenção de peso constante, e as cinzas em mufla a $550{ }^{\circ} \mathrm{C}$ (ARAÚJO, 1995).

A extração lipídica foi feita (FOLCH; LEES; STANLEY, 1957) para a determinação do perfil de AG e índice de peróxido, determinados em cromatógrafo gasoso, marca Konic modelo HRGC 4000A, equipado com coluna CP Sil 88 Tailor Made FAME(Chrompak), coluna $50 \mathrm{~m} \times 0,25 \mathrm{~mm}$ id, filme 0,2, gás de arraste Hidrogênio com fluxo $0,5 \mathrm{~mL} / \mathrm{min}$ (FIRESTONE, 1998). A determinação do colesterol também foi medida (STEWART; GOSSELIN; PANDIAN, 1992).

\subsection{Análise estatística}

O delineamento experimental utilizado para as análises foi inteiramente casualizado (DIC) com 5 tratamentos (T1, T2, T3, T4 e T5). Para avaliar a composição centesimal foram utilizados 5 grupos de amostra com 3 filés de tilápia. Nas análises de ácidos graxos, colesterol e índice de peróxido, foram utilizados 2 grupos para cada um dos tratamentos, cada um contendo 4 porções de filés (VIEIRA, 1999).

Todos os dados foram submetidos à análise de variância (programa estatístico SPSS, versão 11.5, 2002), e quando a análise de variância determinou diferença significativa para uma resposta, os dados da mesma foram submetidos ao teste de Tukey (VIEIRA, 1999).

\section{Resultados e discussão}

\subsection{Composição centesimal}

Comparando-se a umidade dos filés tratados com a dos filés do grupo controle, verifica-se que ocorreu uma perda de água de $0,45 \%$ para o $\mathrm{T} 1 ; 0,76 \%$ para o $\mathrm{T} 2 ; 1,83 \%$ para o $\mathrm{T} 3 \mathrm{e}$ $0,58 \%$ para o T4. Essa perda de água pode estar relacionada com os mecanismos de interação dos compostos sanificantes com a membrana celular. E como as proteínas estromáticas pouco protegem a estrutura física do conjunto de fibras, é possível que ocorra ação sanificante sobre o meio cárneo e, conseqüentemente, uma menor retenção de água nos filés tratados em comparação aos filés do grupo controle. Essas justificativas não foram relatadas na literatura.

A variação média do teor de umidade encontrado nos filés de tilápia, quando submetidos aos tratamentos propostos, foi de 77,16 a 78,60\%. Em avaliação de filés de tilápia abatidos com $700 \mathrm{~g}$ foi encontrada a média de $79,39 \%$ de umidade (FERREIRA et al., 2004), e em filés in natura, médias de 77,91\% (SOUZA et al., 2004). Essas médias assemelharam-se aos valores entre 76 a 83\%, encontrados na literatura (ANKADE, 1989; CONTRERAS-GUZMÁN, 1994; LIMA; ZAPPATA, 1998; SOCCOL; BIATO; OETTERER, 2002), embora tenha sido descrito que esses percentuais podem variar de 58 a $85 \%$, quando analisados diferentes tipos de pescados (CLEMENT; LOVELL, 1994; OGAWA; MAIA, 1999; SIKORSKI, 1990).

Os tratamentos afetaram significativamente $(p<0,05)$ os valores de proteína (Tabela 1). Médias de proteína mais elevadas foram observadas nos tratamentos T3, T2 e T1 (19,73, 19,52 e $19,15 \%$, respectivamente) do que nos tratamentos T4 e T5 (19,05 e 18,71\%, respectivamente).

As médias de proteínas variaram de 18,71 a $19,73 \%$. Esses valores encontram-se próximos aos descritos por alguns autores" que foi de $20,30 \%$ para filés de tilápia abatidos com $585 \mathrm{~g}$. Valores mais baixos de proteína ( 15 a $18 \%$ ) já foram relatados (FERREIRA et al., 2004; SOCCOL; BIATO; OETTERER, 2002), tratando da mesma espécie. Entretanto, também obtiveram um valor de proteína $(25,65 \%)$ que foi superior aos relatados (SOUZA et al., 2004).

Avaliando-se o comportamento dos dados de umidade e proteína, verifica-se que o grupo controle apresentou um maior

Tabela 1. Médias de umidade, proteína, lipídios totais e cinzas (\%) em filés de tilápia.

\begin{tabular}{ccccc}
\hline Tratamentos & Umidade & Proteína & Lipídios & Cinzas \\
\hline T1 & $78,24^{\mathrm{ab}}$ & $19,15^{\mathrm{ab}}$ & $1,44^{\mathrm{e}}$ & $0,19^{\mathrm{ab}}$ \\
T2 & $78,00^{\mathrm{b}}$ & $19,52^{\mathrm{ab}}$ & $1,33^{\mathrm{d}}$ & $0,18^{\mathrm{ab}}$ \\
T3 & $77,16^{\mathrm{c}}$ & $19,73^{\mathrm{a}}$ & $1,74^{\mathrm{c}}$ & $0,20^{\mathrm{a}}$ \\
T4 & $78,14^{\mathrm{ab}}$ & $19,05^{\mathrm{bc}}$ & $3,19^{\mathrm{a}}$ & $0,17^{\mathrm{b}}$ \\
T5 & $78,60^{\mathrm{a}}$ & $18,71^{\mathrm{c}}$ & $2,33^{\mathrm{b}}$ & $0,17^{\mathrm{b}}$ \\
\hline
\end{tabular}

Médias seguidas de letras diferentes, na mesma linha, diferem estatisticamente entre si pelo Teste de Tukey a 5\% de significância; T1 - tratamento com dicloroisocianurato de sódio; T2 - tratamento com dicloroisocianurato de sódio associado ao ultra-som; T3 - tratamento com ozônio; T4 - tratamento com ozônio associado ao ultra-som; e T5 - controle. 
percentual de umidade e um menor percentual de proteínas, ou seja, tratamentos sanificantes causaram uma perda de água que foi confirmada pelo aumento do percentual de proteína nas amostras de filés. Ou seja, a perda de água causou uma concentração significativa nos índices de proteínas no presente estudo. No tratamento T3, esse efeito apareceu, entretanto, no T1, T2 e T4 foi observado, mas com menor intensidade.

Os tratamentos apresentaram diferenças significativas ( $\mathrm{p}<0,05)$ nos lipídios totais (Tabela 1$)$. Os T3 (1,74\%) e T4 $(3,19 \%)$ apresentaram os teores mais elevados de lipídios e os tratamentos com T1 (1,44\%) e T2 (1,33\%) obtiveram os menores teores. Segundo Soares et al. (1998), encontram-se teores de lipídios totais em peixes inteiros e em filés de tilápia de 8,06 e $2,25 \%$, respectivamente (SOARES et al., 1998). É possível que esses resultados sejam devido à variação de gordura entre os peixes escolhidos para compor o lote, em decorrência de regime alimentar que também incluía fitoplâncton existente nos tanques de terra. O fitoplâncton é um alimento natural de alto valor nutritivo constituído de proteínas, lipídios, vitaminas e minerais (BIATO, 2005; KUBITZA, 2000). A variação média encontrada na fração lipídica foi de 1,33 a 3,19\%, estando este intervalo de acordo com os resultados encontrados na literatura, que foram de 2,2 a 3,62\% em filé de tilápia (FERREIRA, 1987; MUJICA, 1988; SOCCOL; BIATO; OETTERER, 2002).

Os teores médios de cinza dos filés de tilápia variaram entre 0,17 a $0,20 \%$ e são apresentados na Tabela 1 .

A fração cinza dos filés de tilápia tratados, somente no T3 $(0,20 \%)$, apresentou diferença significativa em relação ao T4 $(0,17 \%)$ e ao T5 $(0,17 \%)$.

Os resultados médios observados no peixe inteiro e nos filés in natura, para o teor de substâncias minerais, foram de 3,41 e 1,04\% (SOUZA et al., 2004), esses resultados são superiores aos encontrados no presente experimento. Outros autores encontraram teores de 2,3\% para cinzas, utilizando tilápia em seus experimentos (CLEMENT; LOVELL, 1994).

Em análises de 36 peixes de água doce, de espécies diferentes, foi obtido um resultado de substâncias minerais entre 0,81 e 1,95\% para filés, e nos peixes inteiros atingindo até 5,14\%, sendo ambos os tipos de amostras in natura (NATARAJAN; SREENIVASAN, 1961).

O conhecimento quantitativo da composição química dos músculos de peixe de interesse comercial é importante para a formulação de dietas apropriadas, como também na definição de procedimentos técnicos para as indústrias de processamento de pescado (SALES; SALES, 1990). A composição química, dependendo do tipo de processamento a ser utilizado, pode interferir no sabor, na textura e na estabilidade dos ácidos graxos, seja pelo aumento da insaturação ou pela variação dos antioxidantes naturais presentes (SIQUEIRA, 2001).

\subsection{Perfil de ácidos graxos}

Os tratamentos influenciaram os AGS (C14:0 e C16:0); os AGM (C16:1 $\omega$ 7, C18:1 $\omega 9$ e C20:1 $\omega$ 11); e os AGP (C18:3 $\omega 3$, C18:3 $\omega$ 6, C20:4 $\omega$ 6, C20:5 $\omega$ 3, C22:5 $\omega$ 6, C22:5 $\omega$ 3, C22:6 ( 3). Como a ação sanificante do dicloroisocianurato de sódio e do ozônio está relacionada com o poder oxidante (MACEDO, 2000), é possível que o efeito significativo dos tratamentos sobre os diferentes ácidos graxos seja resultado da oxidação de alguns ácidos graxos (CHEN et al., 1992; MENZEL, 1984). Outro fator que também pode ter determinado a diferença é a variação entre o material experimental, que apresentou peso médio de $800 \mathrm{~g}( \pm 50 \mathrm{~g})$.

Foi postulado que o ozônio pode gerar a formação de substâncias tóxicas em alimentos, resultado da oxidação de tecidos protéicos ou ácidos graxos insaturados do mesmo (MENZEL, 1984). Contudo, sendo avaliada a atividade mutagênica do ozônio, tanto em gorduras quanto em extratos solúveis de camarão, foi detectado que a imersão em solução de ozônio $\left(5 \mathrm{mg} \cdot \mathrm{L}^{-1}\right.$ durante 120 minutos) não induziu à formação de produtos mutagênicos nos mesmos (CHEN et al., 1992).

A análise de variância $(\mathrm{p}<0,05)$ demonstrou diferença significativa em fração lipídica de AGS, AGM e AGP entre os tratamentos propostos, como pode ser avaliado na Tabela 2.

Os ácidos graxos saturados apresentaram diferença entre os tratamentos T3, T4 e T5, com as respectivas médias de 37,90, 33,50 e $36,20 \%$, observando-se que o tratamento com ozônio foi o que mais preservou a fração AGS. Os tratamentos T1 e T2 $(34,90$ e $34,80 \%)$ não diferiram entre si, mas foram diferentes dos tratamentos T3, T4 e T5 (39,30, 36,30 e 39,10\%) para AGM, mostrando que o tratamento com ozônio foi o que mais preservou a fração AGM. Os AGP não apresentaram diferença entre os tratamentos T1 e T2 (23 e 22,60\%) e os grupos T3, T4 e T5 $(18,30,20,40$ e $17,70 \%)$ diferiram entre si, tendo os tratamentos com dicloroisocianurato de sódio apresentado as maiores médias. As médias de AG estão representadas na Tabela 2.

Os AG C18:2 $\omega 6$ e C18:3 $\omega 3$ são considerados essenciais, pois são os precursores para a síntese de muitos AGP, como os ácidos C20:4 $\omega$ 6, C20:5 $\omega 3$ e C22:6 $\omega 3$ (SPECTOR, 1999). Os AG derivados da ação de enzimas, como as cicloxigenases e lipoxigenases, formam os eicosanóides, substâncias moduladoras de muitas funções vitais, participando de processos secretórios, digestivos, reprodutivos, imunológicos e circulatórios (MANCINI-FILHO; CHEMIN, 1996).

Entre os AGP, o ácido linoléico (C18:2 $\omega$ 6) encontrado nos filés tratados (Tabela 2) apresentou percentual médio superior $(14,20 \%)$ no grupo T3 quando comparado aos dos outros tratamentos. Possivelmente, este fato deve-se a uma menor intensidade na reação de oxidação, levando a uma maior preservação desses AGP, sendo o ozônio altamente volátil (GARCIA; MOUNT; DAVIDSON, 2003) e não permanecendo no produto tempo suficiente para que essa reação fosse intensificada. A temperatura dos tratamentos pode também ter auxiliado, retardando essa reação (TORRES et al., 1996). Em estudo dos diferentes métodos de cocção de filés de tilápia, foi observado percentual $(14,27 \%)$ semelhante ao do ácido linoléico (C18:2 $\omega$ 6) em filés de tilápia crus (FERREIRA et al., 2004).

Comparado ao grupo controle, não houve diferenças significativas no perfil de ácidos graxos $\omega 6$ extraídos nos diferentes tratamentos $(p>0,05)$. Contudo, foi identificado um aumento no teor de ácidos graxos $\omega 3$ obtidos quando do tratamento dos filés com dicloroisocianurato de sódio ou ozônio, associados ao 
Tabela 2. Média de ácidos graxos (\% lipídios totais) em filés de tilápia.

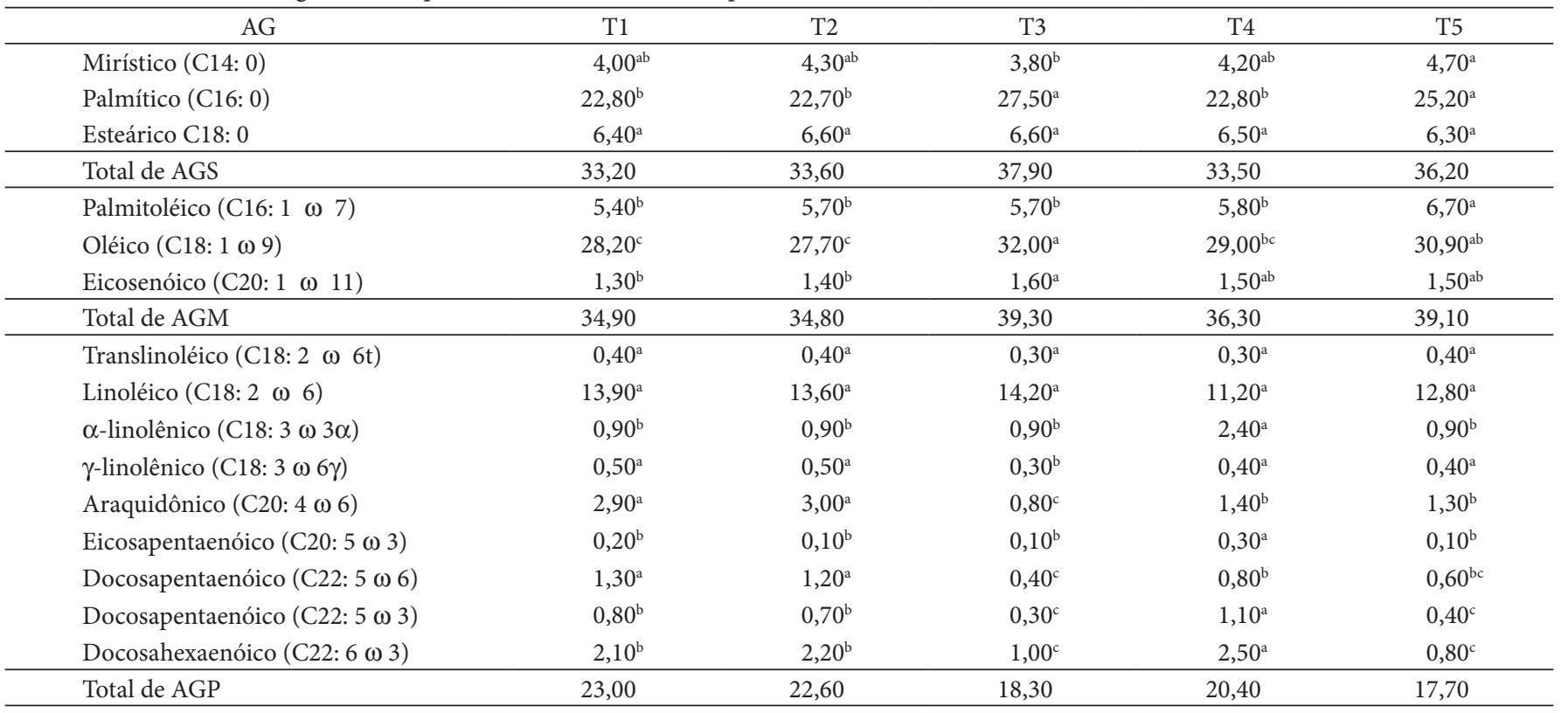

Médias seguidas de letras diferentes, na mesma linha, diferem estatisticamente entre si pelo Teste de Tukey a 5\% de significância; T1 - dicloroisocianurato de sódio; T2 - dicloroisocianurato de sódio associado a ultra-som; T3 - ozônio; T4 - ozônio associado a ultra-som; e T5 - controle.

ultra-som $(\mathrm{p}<0,05)$, porém não verificado na ausência deste último.

O ultra-som é conhecido por propiciar um conjunto de alterações na estrutura de ácidos graxos insaturados, em curto período de tempo ( 15 a 30 minutos), temperatura ambiente e freqüência de $20 \mathrm{kHz}$ (LIE KEN JIE; KALLURI, 1996b), tais como deidrobrominação, formando derivados acetilênicos com grupos funcionais adicionados (LIE KEN JIE; KALLURI, 1996a); epoxidação de cadeias longas na presença de ácido cloroperoxibenzóico (LIE KEN JIE; LAM, 1995); e clivagem oxidativa de ligações acetilênicas de ácidos graxos (LIE KEN JIE; KALLURI, 1996a). Além disso, o emprego de ultra-som tem sido auxiliar na síntese de ácido santálbico e fracionamento em óleo de semente de Santalum album (LIE KEN JIE et al., 1997), síntese de ácidos graxos com derivados de anel de pirazolona (LIE KEN JIE; LAU, 1997), e na oxidação e abertura de anel furanóide de ácidos graxos C18 modificados.

O aumento encontrado no teor de ácidos graxos $\omega 3$ extraídos, quando tratados com ultra-som, pode estar relacionado ao seu efeito sobre a homogeneização e emulsificação de substratos oleofínicos em contato próximo, sob a ação de reagentes oxidantes, o que não tem sido observado na supressão do ultra-som (LIE KEN JIE; KALLURI, 1996b). Em paralelo, esse efeito parece estar intensificado pela condução aumentada no ambiente polar e de alta constante dielétrica da água utilizada para os tratamentos. Análises por ressonância magnética nuclear e espectroscopia de massa de alta resolução, contudo, sugerem o emprego de ultra-som na identificação de centros insaturados (dupla e tripla ligações) na cadeia alquila de ácidos graxos (LIE KEN JIE; KALLURI, 1996a).

Analisando-se três espécies de pescado brasileiro, matrichã (Brycon cephalus), piraputunga (Brycon microlepis) e piracan- juba (Brycon orbignyanus), foi encontrado um total de AGS de 33,63 a 41,86\%; de AGM de 46,97 a 57,20\% e de AGP de 6,54 a 17,88\% (MOREIRA et al., 2001), resultados estes semelhantes aos obtidos no presente estudo.

Em pesquisa com irradiação de tilápia do Nilo, obteve-se um total de AGS de 32,5 a 47,5\% em filés não irradiados e de 33 a $52 \%$ para os irradiados; de AGM de 44 a $44,8 \%$ em filés não irradiados e 39,9 a 44,6\% em filés irradiados; de AGP de 7,3 a $21,4 \%$ em filés não irradiados e 7,2 a 22,9\% para os irradiados (SIQUEIRA, 2001). Quando comparados os tratamentos por irradiação com os de dicloroisocianurato de sódio e ozônio (associados ou não ao ultra-som), foram observados intervalos superiores nos grupos irradiados para AGS e AGM; e os AGP apresentaram valores inferiores. Em ambas as pesquisas, os filés não tratados obtiveram percentuais compatíveis.

Analisando-se tilápia (Oreochromis niloticus) e curimbatá (Prochilodus serofa), em relação à composição de ácidos graxos, foram encontrados valores de $41,7 \%$ para AGS, $49,9 \%$ para AGM e 17,4\% para AGP, em tilápia. No curimbatá foram detectados os seguintes percentuais: $42 \%$ para AGS, $36 \%$ para AGM e 21\% para AGP (MAIA; RODRIGUEZ-AMAYA, 1993; MAIA; RODRIGUEZ-AMAYA; FRANCO, 1994).

Foram analisadas três espécies de pescado de água doce quanto ao conteúdo de ácidos graxos: tilápia (Tilapia mossambica), "barbus" (Barbus carnaticus) e cobra do mar (Ophichthidae) e encontrados os teores de 33,7 a 49,3\% para AGS, de 29,9 a $37,5 \%$ para AGM e de 18,1 a $33,2 \%$ para AGP nas três espécies, respectivamente (OGAWA; MAIA, 1999).

Os lipídios contidos em pescados apresentam grande quantidade de ácidos graxos insaturados, suscetíveis à oxidação em presença do oxigênio. Também o período de coleta dos peixes pode exercer efeitos significativos sobre a composição de alguns ácidos 
graxos, como oléico e $a$-linoléico (BEIRÃO et al., 2003; OLIVEIRA; MATSUHITA; AGOSTINHO, 2000; OLIVEIRA et al., 2005).

A oxidação é uma das principais causas de deterioração da qualidade de produtos cárneos. A susceptibilidade do tecido muscular à oxidação deve-se à sua alta concentração de catalisadores (ferro e hemoglobina) e a de lipídios. Os lipídios oxidados podem reagir com outros componentes do alimento, como proteínas, carboidratos e vitaminas (CÂNDIDO; NOGUEIRA; SGARBIERI, 1998; HULTIN, 1994). A ação sanificante dos tratamentos se deu pela capacidade de oxidação de ambos (MACEDO, 2000; RICE, 1996).

Os percentuais de ácidos graxos, em todos os grupos, observados nesta pesquisa, quando comparados com valores descritos para tilápia fresca, pelos pesquisadores já citados, mantiveramse estáveis após os tratamentos (MAIA; RODRIGUEZ-AMAYA, 1993; MAIA; RODRIGUEZ-AMAYA; FRANCO, 1994; SIQUEIRA, 2001).

Os teores de AGP encontrados nestes peixes podem ser influenciados pelos teores de ácidos graxos AGP existentes nas rações fornecidas e pelo peso dos peixes.

\subsection{Colesterol e índice de peróxido}

Os teores médios de colesterol encontrados em filés de tilápias submetidos aos tratamentos revelaram diferença pela análise de variância $(p<0,05)$. As médias dos grupos de filés tratados com ozônio e do grupo controle foram semelhantes (54,65 e $54,77 \mathrm{mg} .100 \mathrm{~g}^{-1}$, respectivamente), mas foram diferentes dos grupos tratados com dicloroisocianurato $\left(45,04 \mathrm{mg} .100 \mathrm{~g}^{-1}\right)$, dicloroisocianurato associado ao ultra-som (43,94 mg.100 g-1) e ozônio associado ao ultra-som $\left(45,93 \mathrm{mg} \cdot 100 \mathrm{~g}^{-1}\right)$. As médias obtidas podem ser observadas na Tabela 3 .

No grupo T2 (43,94 mg.100 g-1), obteve-se uma redução mais acentuada quando comparado com o controle $\left(54,77 \mathrm{mg} .100 \mathrm{~g} \mathrm{~g}^{-1}\right)$, provavelmente por uma ação oxidante mais acentuada do dicloroisocianurato associado ao ultra-som nos ácidos graxos saturados, que podem ser transformados em óxidos de colesterol.

Os teores de colesterol encontrados em algumas espécies domésticas tradicionalmente consumidas foram de $36,3 \mathrm{mg} .100 \mathrm{~g}^{-1}$ para frangos, $51 \mathrm{mg} .100 \mathrm{~g}^{-1}$ para bovinos nelore, e de 62,03-76,9 mg.100 g ${ }^{-1}$ para ovinos (NOGUEIRA; BRAGAGNOLO, 2000; PRADO, 1999; ROWEL et al., 1999; SALES et al., 1999).

Os filés tratados com os sanificantes apresentaram valores inferiores aos encontrados para bovinos e ovinos, e superiores aos encontrados para frangos (NOGUEIRA; BRAGAGNOLO, 2000; PRADO, 1999; ROWEL et al., 1999; SALES et al., 1999). Foram observadas, nos tratamentos conjugados com o ultrasom (T2 43,94 mg.100 g ${ }^{-1}$ e T4 45,93 mg.100 g-1) e no tratamento com dicloroisocianurato de sódio (T1 45,04 mg.100 g ${ }^{-1}$ ), médias inferiores, quando comparadas ao tratamento com ozônio $\left(54,65 \mathrm{mg} \cdot 100 \mathrm{~g}^{-1}\right)$. Todos os tratamentos apresentaram médias inferiores a do controle (54,77 mg.100 g $\left.{ }^{-1}\right)$.

Os teores médios de índices de peróxido encontrados em filés de tilápia submetidos aos tratamentos não revelaram dife-
Tabela 3. Média de colesterol (mg.100 $\mathrm{g}^{-1}$ de lipídios) e índice de peróxido (meq.kg-1 da fração lipídica) de filés de tilápia submetidos aos tratamentos.

\begin{tabular}{ccc}
\hline Tratamentos & $\overline{\mathrm{x}}$ de colesterol & $\overline{\mathrm{x}}$ de índice de peróxido \\
\hline T1 & $45,04^{\mathrm{b}}$ & $14,78^{\mathrm{a}}$ \\
T2 & $43,94^{\mathrm{b}}$ & $6,07^{\mathrm{a}}$ \\
T3 & $54,65^{\mathrm{a}}$ & $15,79^{\mathrm{a}}$ \\
T4 & $45,93^{\mathrm{b}}$ & $9,62^{\mathrm{a}}$ \\
T5 & $54,77^{\mathrm{a}}$ & $39,57^{\mathrm{a}}$ \\
\hline
\end{tabular}

Médias seguidas de mesma letra são estatisticamente iguais entre si pelo teste de Tukey ao nível de $5 \%$ de probabilidade $(\mathrm{p}<0,05)$. T1 - tratamento com dicloroisocianurato de sódio; T2 - tratamento com dicloroisocianurato de sódio associado ao ultra-som; T3 - tratamento com ozônio; T4 - tratamento com ozônio associado ao ultra-som; e T5 - controle.

rença estatística segundo análise de variância $(\mathrm{p}>0,05)$, apesar dos valores médios terem sido bastante diferentes, como pode ser observado na Tabela 3. Isto se deve a um alto coeficiente de variação decorrente da variável muito instável.

É conhecido que as bactérias lácticas e os Enterococcus produzem vários compostos bactericidas, incluindo os ácidos orgânicos, que fazem baixar o $\mathrm{pH}$, o peróxido de hidrogênio, as enzimas bacteriolíticas e as bacteriocinas (DEMARIGNY et al., 1996; GIRAFFA, CARMINATTI; NEVANI, 1997). Alguns desses compostos também são responsáveis pelas características organolépticas dos queijos e outros alimentos, e ao mesmo tempo inibem parte dos microrganismos da microflora indesejável (HÉRARD et al., 1993; NETTLES; BAREFOOT, 1993).

A produção de ácidos e de peróxido de hidrogênio pela flora láctica e Enterococcus também foi registrada por outros autores, como Guerra e Bernardo (2001), em estudo in vitro, com agentes microbianos com capacidade de inibição de efeitos biológicos com eventual relevância tecnológica e sanitária. Portanto, os resultados obtidos no presente estudo, em que o índice de peróxido foi maior nas amostras controle, podem ser justificados por terem sido eliminadas as bactérias (possivelmente Enterococcus) produtoras desse composto pelos métodos sanificantes utilizados.

A peroxidação de AGP in vivo leva à formação de malonaldeído, que pode provocar ligações cruzadas nas lipoproteínas de baixa densidade, causando acúmulo de colesterol no vaso sangüíneo. Os ácidos graxos peroxidados inibem a produção de prostaciclina, produzida pelo endotélio vascular, conhecida como potente inibidor da agregação plaquetária no vaso sangüíneo (A.O.A.C., 1990). Portanto, é indicada a ingestão de altas taxas de AGP, desde que associadas proporcionalmente com antioxidantes, como vitamina $\mathrm{C}, \mathrm{E}$ e $\beta$-caroteno para evitar a peroxidação lipídica (PEREIRA, 2003).

Diante dos resultados obtidos no presente estudo, pode-se dizer que os grupos T2 (6,07 meq. $\left.\mathrm{kg}^{-1}\right)$ e T4 (9,62 meq.kg-1) obtiveram menor índice de peróxido, sendo, portanto, os métodos de sanificação que não causariam danos à saúde quanto ao aspecto de produção de radicais livres.

\section{Conclusões}

Observou-se que em todos os tratamentos houve preservação dos componentes químicos presentes na carne de tilápia, 
ocorrendo apenas uma diminuição do teor de umidade, sendo que o ozônio provocou a maior diminuição desse componente, levando a um aumento da concentração nos teores de proteína, lipídios e cinzas. O controle apresentou maior percentual de umidade.

Todos os agentes usados como sanificantes alteraram o perfil de ácidos graxos em tilápias.

Os teores médios de colesterol encontrados em filés de tilápia submetidos aos tratamentos mostraram-se diferentes pela análise de variância $(\mathrm{p}<0,05)$. Os tratamentos com dicloroisocianurato, dicloroisocianurato associado ao ultra-som e ozônio associado ao ultra-som interferiram nas médias de colesterol obtidas.

Os teores médios de índices de peróxido encontrados em filés de tilápia, submetidos aos tratamentos, não revelaram diferenças estatísticas segundo análise de variância $(p>0,05)$.

\section{Agradecimentos}

Universidade José do Rosário Vellano - UNIFENAS; Universidade Federal de Lavras - UFLA; CAPES; e CNPq

\section{Referências bibliográficas}

A.O.A.C. Association Official Analytical Chemistry. Official methods of analysis of the A.O.A.C. 14. ed. Washington, DC: A.O.A.C., 1990.

ANKADE, G. R. Technical note: improved utilization of stunded tilapia spp. Journal Food Science and Technology International, v. 24, p. 20-26, 1989.

ARAÚJO, J. M. A. Química dos Alimentos. 1. ed. Viçosa: UFV, 1995. $335 \mathrm{p}$.

BEIRÃO, L. H et al. Curso Tecnologia Para Aproveitamento Integral Do Pescado; Instituto de Tecnologia de Alimentos. Centro de Tecnologia da Carne. II Curso de Tecnologia para Aproveitamento Integral do Pescado: 9-11 de junho de 2003. Campinas: ITAL/ CTC, 2003.79 p.

BIATO, D. O. Detecção e controle do off flavor em tilápia do Nilo (Oreochromis niloticus) por meio de depuração e defumação. Piracicaba, 2005.105 p. Dissertação. Escola Superior de Agricultura Luis de Queiroz.

BOBBIO, F. O; BOBBIO, P. A. Introdução a química de alimentos. 2. ed. São Paulo: Varella, 1992. 223 p.

CÂNDIDO L. M. B; NOGUEIRA, A. K.; SGARBIERI, V. Propriedades funcionais de concentrado protéico de pescado preparado por vários métodos. Brasilian Journal of Food Tecnology. v. 1, n. 1/2, p. 77-89, 1998.

CHEN, H. C. et al. Bactericidal e mutagenic effects of ozone on shrimp (Penaeus- Monodon) meat. Journal of Food Science. v. 57, n. 4, p. 923-927.1992.

CLEMENT, S.; LOVELL, R. T. Comparison of culture Nile tilapia (Oreochromis niloticus) and channel catfish (Ictalurus punctatus). Aquaculture, v. 119, p. 299-310, 1994.

CONTRERAS-GUZMÁN, E. Bioquímica de pescados e derivados. Jaboticabal:FUNEP, 1994. 409 p.

DEMARIGNY, Y. et al. Influence of Raw Milk Microflora on the Characteristics of Swiss-Type Cheeses. I. Evolution of Microflora During Ripening and Characterization of Facultative
Heterofermentative Lacto-bacilli. Le Lait, v. 76, n. 44, p. 371-378, 1996.

FERREIRA, M. W. et al. Perfil de ácidos graxos de tilapia do Nilo (Oreochromis niloticus) In: XIX CONGRESSO DE CIÊNCIA E TECNOLOGIA DE ALIMENTOS: ESTRATÉGIAS PARA DESENVOLVIMENTO. CD - Room. Recife 2004. Anais... Recife, 2004.

FERREIRA, S. O. Aplicação de tecnologia a espécies de pescados de água doce visando atender a agroindústria rural. Piracicaba, 1987.122 p. Dissertação (Mestrado em Ciência e Tecnologia de Alimentos) - Escola Superior de Agricultura "Luiz de Queiroz", Universidade de São Paulo.

FIRESTONE, D. Official methods and recommended practices of the American Oil Chemists Society, AOCS. v. I - II5 ed. Champaign: D. Firestone, American Off Chemists' Society, 1998 (MÉTODOS Ce 1-62; Ce 1b-89; Ce 1c-89).

FOLCH, J.; LEES, M.; STANLEY, G. H. S. A simple method for the isolation and purification of total lipids from animal tissues. The Journal of Biological Chemistry, v. 226, n. 1, p. 497-509, 1957.

FULLER, J. C.; JIALAL, I. Effects of antioxidants and fatty acids on lowdensity-lipoprotein oxidation. The American Journal of Clinical Nutrition, Bethesda, v. 60, p. 1010-13, 1994

GARCIA, A.; MOUNT, J. R.; DAVIDSON, P. M. Ozone and Chlorine Treatment of Minimally Processed Lettuce. Journal of Food Science, Chicago - USA, v. 68, n. 9, p. 2747-2751, 2003

GIRAFFA, G.; CARMINATTI, D.; NEVANI, E. Enterococci Isolated from Dairy Products: a Review of Risks and Potential Technological Use. J. Food Protection, Iowa - USA, v. 60, p. 732-738, 1997.

GUERRA, M. M.; BERNARDO, F. M. A. Caracterização de efeitos inibidores de Listeria monocytogenes Scott A, produzidos pela microflora de maturação de queijos do Alentejo. Revista Portuguesa de Ciências Veterinárias, Lisboa, v. 96, n. 538, p. 65-69, 2001.

HÉRARD, Y. et al. Les Bacteriocines Contre Listeria: Une Nouvelle Familla de Proteínas. Le Lait., v. 73, p. 207-213, 1993.

HULTIN, H. O. Oxidation of lipids in seafood. In: Seafood Chemistry, Processing; Technology and Quality. London: Blackie A\&P, 1994. p. 49-74. (Ed. by F. Shahidi \& J.R. Botta).

KUBITZA, F. Tilápia: Tecnologia e planejamento na produção comercial. São Paulo: Degaspari, 2000. 289 p.

LIE KEN JIE, M. S. F; LAM, C. K. Ultrasound-assisted expoxidation reaction of long-chain unsaturated fatty esters. Ultrasonic Sonochem. v. 2, p. S11-S14, 1995.

LIE KEN JIE, M. S. F.; KALLURI, P. Ultrasound-assisted oxidative cleavage of acetylenic and ethylenic bonds in unsaturated fatty esters with potassium permanganate. Lipids. v. 31, n. 12, p. 1299 1301, 1996a.

Ultrasound-assisted synthesis of santalbic acid and a study of triacylglycerol species in santalum album (Linn.) seed oil. Lipids. v. 31, n. 10, p.1083-1089, 1996b.

LIE KEN JIE, M. S. F.; PASHA, M. K.; LAM, C. K. Ultrasonically stimulated oxidation reactions of 2,5-disubstituted $\mathrm{C}_{18}$ furanoid fatty ester. Chemistry and Physics of Lipids, v. 85, p. 101-106, 1997.

LIE KEN JIE, M. S. F.; LAU, M. M. L. Ultrasound-assisted synthesis of pyrazole fatty ester derivatives from a key $\mathrm{C}_{18}$ keto-allenic ester. Chemistry and Physics of Lipids, v. 101, n. 2, p. 237-242, 1999.

LIMA, M. F. V.; ZAPPATA, J. F. F. Efeito do ácido lático e do lactato de sódio sobre as características físicas, químicas e sensoriais de filés frescos de tilápia - do - nilo (Oreochromis niloticus). In: CONGRESSO BRASILEIRO DE CIÊNCIA E TECNOLOGIA DE 
ALIMENTOS, 16., 1998, Rio de Janeiro. Anais... Rio de janeiro: SBCTA, 1998. p. 739-742.

MACEDO, J. A. B. Águas \& Águas. Juiz de Fora: Ortofarma, 2000. $505 \mathrm{p}$.

MAIA E. L.; RODRIGUEZ-AMAYA, D. B. Avaliação de um método simples e econômico para metilação de ácidos graxos com lipídios de diversas espécies de peixes. Revista do Instituto Adolfo Lutz, v. 53 , n. $1 / 2$, p. 27-35, 1993.

MAIA E. L.; RODRIGUEZ-AMAYA, D. B.; FRANCO, M. R. B. Fatty acids of the total, neutral, and phospholipids of the Brazilian freshwater fish Prochilodus scrofa. Journal of Food Composition and Analysis, v. 6, n. 4, p. 240-251, 1994.

MANCINI-FILHO, J.; CHEMIN, S. Implicações nutricionais dos ácidos graxos trans. Óleos e Grãos, São Caetano do Sul, v. 31, n. 1, p. 41-45, 1996.

MENZEL, D. B. Ozone: an overview of its toxicity in man and animal. J. Toxical. Environ. Health., v. 13, n. 2-3, p. 183-204, 1984.

MOREIRA, A. B. et al. Fatty acids profile and cholesterol contents of three Brazilian brycon freshwater fishes. J. Food Comp. Anal., v. 14, n. 6, p. 565-74, 2001.

MUJICA, P. Y. C. Avaliação da qualidade organoléptica, química, e microbiológica de tilápia-do-nilo (Oreochromis niloticus), mantida à temperatura ambiente e sob gelo. Viçosa, 1988. 75 p. Dissertação (Mestrado em Engenharia de Alimentos.) Universidade Federal de Viçosa.

NATARAJAN, V. M.; SREENIVASAN, A. Proximated and mineral composition of freshwater fishes. Indian Journal of Fisheries., Indian, v. 8, n. 2, p. 422-29, 1961.

NETTLES, C. G.; BAREFOOT, S. F. Biochemical and Genetic Characteristics of Bacteriocins of Food- Associated Lactic Acid Bacteria. J. Food Protection., Iowa - USA, v. 56, p. 338-356, 1993.

NOGUEIRA, G. C.; BRAGAGNOLO, N. Frango caipira, coelho e pato: colestrol, lipídios totais e composição em ácidos graxos. In: CONGRESSO BRASILEIRO DE CIÊNCIA E TECNOLOGIA DE ALIMENTOS. 17, 2000, Fortaleza, CE. Anais... Fortaleza: CBCTA, 2000.

OGAWA, M.; MAIA, E. L. Manual de pesca: Ciência e Tecnologia de Pescado. São Paulo: Varela. 1999. v. 1. 430 p.

OLIVEIRA, E. R. N.; MATSUHITA, M; AGOSTINHO, A. A. Ácidos em filés de hypopythalmus edentattus (mapará ou sardela) capturados no reservatório de Itaipu - PR. In: CONGRESSO BRASILEIRO DE CIÊNCIA E TECNOLOGIA DE ALIMENTOS. 17. Fortaleza, 2000. Resumo... Fortaleza: Sociedade Brasileira de Ciência e Tecnologia de Alimentos, 2000. v. 2. p. 5-23.

OLIVEIRA, N. M. S. et al. Perfil de ácidos graxos, colesterol e peróxido em filés de tilápia (Oreochromis niloticus) submetidos tratamentos de sanitização. In: II Congressos Latino-Americano e VIII Congressos Brasileiro de Higienistas de Alimentos. 2005, Búsios - RJ. Anais dos Congressos II Latino-Americano e VIII Brasileiro de Higienistas de Alimentos: Alimento, Saúde e Meio Ambiente - As tendências do século 21. Higiene Alimentar. v. 19, n. 130, abr. 2005.
PEREIRA, M. C. A. Características de fontes lipídicas comerciais e seus efeitos sobre o perfil lipídico plasmático, hepático e cerebral de ratos. Lavras, 2003, 125p. Dissertação (Mestrado em Ciência dos Alimentos) - UFLA.

PRADO, O. V. Qualidade da carne de cordeiro Santa Inês e Bergamácia abatidos em diferentes pesos. Lavras, 1999. 109 p. Dissertação (Mestrado em Zootecnia)- Universidade Federal de Lavras.

RICE, R. G. Application of ozone in water and wastewater treatment. In: RICE, R. G. et. al. Analytical aspects of ozone: treatment of water and wastewater. Michigan: Edited Lewis Publishers, Inc., 1986. p. 7-26.

ROWEL, A. et al. Muscle composition and fatty acid profile in lambs fattened in dry lot or pasture. Meat Science, Oxford, v. 51, n. 4, p. 283-388, apr. 1999.

SALES, R. O.; SALES, A. M. Estudo da composição química e rendimento de dez espécies de pescado de água doce de interesse comercial nos açudes do nordeste brasileiro. Ciências Agronômicas, Fortaleza, v. 1/2, n. 21, p. 27-30, 1990.

SALES, J. et al. Cholesterol content and fatty acid composition of rhea meat. Meat Science, Oxford, v. 53, n. 2, p. 73-75, oct. 1999.

SIKORSKI, Z. E. Composición nutritive de los principales grupos de organismos alimenticios marinos. Tecnología de los productos del mar: recursos. Zaragoza: Acribia, 1990. p. 41-72.

SIQUEIRA, A. A. Z. C. Efeitos da irradiação e refrigeração na qualidade e no valor nutritivo da tilápia (Oreochromis niloticus). 2001, 137p. Dissertação (Mestrado em Ciência e Tecnologia de Alimentos) - Escola Superior de Agricultura Luiz de Queiroz, Piracicaba - SP, 2001.

SOARES, V. F. M. et al. Histamine levels and physic - chemical and sensory quality of frozen fish fillet. Ciên.Tecnol. Alimentos, Campinas. v. 18, n. 4, oct./dec. 1998.

SOCCOL, M. C. H.; BIATO, D.; OETTERER, M. Acidificação como complemento para extensão da vida útil da tilápia (Oreochromis niloticus) minimamente processada. In: CONGRESSO BRASILEIRO DE CIÊNCIA E TECNOLOGIA DE ALIMENTOS, 18. Porto Alegre, 2002. Anais... Porto Alegre: SCBTA, 2002. p. 224-228.

SOUZA, M. L. R et al. Defumação da tilápia do Nilo (Oreochromis niloticus) inteira eviscerada e filé: aspectos referentes às características organolépticas, composição centesimal e perdas ocorridas no processamento. Rev. Bras. Zootec, Viçosa, v. 33, n. 1, jan./fev., 2004.

SPECTOR, A. A. Essentialy of fatty acids. Lipids, Champaign, v. 34, p. S1-S3, 1999.

STEWART, G.; GOSSELIN, C.; PANDIAN, S. Selected ion monitoring of tert-butyldimethylsilyl cholesterol ethers for determination of total cholesterol content in foods. Food Chemistry, Oxford, v. 44, n. 55 , p. $377-380,1992$.

TORRES, E. A. F. S et al. Estudos das propriedades desinfetantes do ozônio em alimentos. Higiene Alimentar, São Paulo, v. 10, n. 42, p. 18-23, mar./abr., 1996.

VIEIRA S. Estatística Experimental. 2. ed. São Paulo: Editora Atlas, 1999. $192 \mathrm{p}$. 